\title{
ANALYSIS OF THE RELEVANT PARAMETERS ON SMALL SCALE OF NAVIGABLE ABNORMAL SHIP MODEL
}

\author{
Cai Chuang, A.P. \\ Lei Penghua, Engineer \\ Cai Xinyong, Engineer \\ Chongqing Jiaotong University, China
}

\begin{abstract}
At present, ship model tests are based on the normal mode at home and abroad. With the development and application of abnormal hydraulic model, it is necessary to study abnormal ship model. The similarity criterion of abnormal ship model is deduced from the similarity theory of normal hydraulic model in this paper. Some factors that affect the maneuverability of the abnormal ship model are discussed by theoretical analysis of ship maneuvering. The influence of the $K$ and $T$ index of different variable rate on the abnormal ship model maneuvering and the dimensional effect of the abnormal ship model are obtained, which can be used as a reference for the study of the abnormal ship model.
\end{abstract}

Keywords: hydraulic model; similarity criterion; abnormal ship model

\section{INTRODUCTION}

Since the 1970s, the small scale ship model technology is often used in domestic research on the navigable water problem, which makes it has a rapid development in the test research of hydraulic model. At present, the research on normal ship model has been more mature in china. It is more intuitive and scientific for the use of ship model test to study navigable condition than only use of water flow model.

Ship model test is designed to simulate the actual ship motion properties of navigation, which requires the model ship have certain similarity, including geometric similarity, kinematic similarity and dynamic similarity. It is very difficult to do the same. Such as in the geometric similarity, even if the ship models of the length, width and height with the same scale of actual ship, it cannot guarantee completely similar in shape. In kinematic similarity, if the line speed, the angular velocity, linear acceleration and angular acceleration of ship model are required to have the same ratio. However, due to the relatively large ship model resistance, it is required to accelerate the speed of the ship model propeller, resulting in the propeller can't meet the similar [1]. It is impossible to satisfy the similarity of the Reynolds number and the viscous coefficient in the motion similarity. So there is a scale effect between the ship model and actual ship. The emphasis is different in the practical application of ship model, according to the purpose of the experiment, we have to grasp the main contradiction, make some fixed rate for the ship model test results, so that it can more accurately express the real ship.

But in many practical situations, because of the restriction of the test site, even if the above problems can be solved, we cannot use the normal ship model to test, then we must consider the application of the abnormal ship model to solve problem. 


\section{EXISTING PROBLEMS OF ABNORMAL SHIP MODEL}

The ship model test is the simulation of the actual ship's movement which is in the water flow, so the reduction ratio of the ship model is more consistent with the water flow model, $\lambda_{h}$ and $\lambda_{l}$ of ship model should be unified with water flow model. However, in the abnormal ship model $\lambda_{h} \neq \lambda_{l}$, there are several problems in the design of the abnormal ship model:

(1)Abnormal of ship form: Generally, $\lambda_{h}<\lambda_{l}$, caused the form of ship model is taller than actual ship, rate of change is bigger than actual ship.

(2) Abnormal of propeller: Geometric changes in the abnormal ship mode, it is obviously impossible for propeller to be designed as an ellipse with the same geometry according to the theory.

(3)Abnormal of rudder: Similar to the abnormal condition of the propeller, shape of rudder is different from the real ship because of different abnormal ratio in two directions.

\section{SIMILAR PROBLEM OF ABNORMAL SHIP MODEL}

In the experiment, the abnormal ship model is also affected by the gravity and resistance, and follow the same principles of gravity and resistance like other abnormal models.

\section{GRAVITY SIMILARITY CRITERION}

Gravity is expressed as,

$$
G=m g=\rho V g
$$

Then its dimension is,

$$
[G]=[\rho][L]^{2}[H]^{2} /[T]^{2}
$$

Therefore, the gravity ratio between ship model and actual ship can be obtained by gravity similarity criterion,

$$
\lambda_{G}=\lambda_{\rho} \lambda_{l}^{2} \lambda_{h} \lambda_{g}
$$

The ship model test and the actual ship are carried out under the same gravity condition, that is,

$$
\lambda_{g}=1
$$

So

$$
\lambda_{G}=\lambda_{\rho} \lambda_{l}^{2} \lambda_{h}
$$

Inertial force and gravity are the same type of force under the gravity similarity criterion, their similarity coefficients should be equal, but horizontal ratio rule of ship model is not the same as vertical ratio, so we should discuss it separately. Inertia force is expressed as,

$$
F=m a=\rho V L / t^{2}
$$

Then its dimension is:

$$
[F]=[\rho][L]^{2}[H][L] /[T]^{2}
$$

We can obtain:

$$
\lambda_{G} / \lambda_{F}=\lambda_{l} / \lambda_{h}=e
$$

Therefore, it is impossible to make abnormal ship model to meet the gravity similarity criterion. In the design of abnormal ship model, the quality of the ship model should be as far as possible to meet its vertical ratio, and its inertia force to meet horizontal ratio rule.

\section{RESISTANCE SIMILARITY CRITERION}

It is difficult to discuss resistance of ship because of complex ship form, we can follow the principle of the flat panel which is made by Fu Rude. Fu Rude suggested that the resistance of the ship on the surface of the water can be approximated as the resistance of plate with same length, width and the same wetted perimeter [2].

According to,

$$
F_{c}=\mu A d v / d x=\mu L H d v / d x
$$

The dimension of the friction force can be obtained,

$$
\left[F_{c}\right]=[\mu \rrbracket[L \rrbracket[H][V] /[L]=[\mu][H][V]
$$

Deduced from above,

$$
\lambda_{F_{c}}=\lambda_{\mu} \lambda_{h} \lambda_{v}
$$

According to dynamic similarity principle, we can obtain,

$$
\lambda_{l} \lambda_{\mu} \lambda_{u}=\lambda_{\rho} \lambda_{l}^{3} \lambda_{h} / \lambda_{t}^{2}
$$

The ship model can be approximated as uniform linear motion in the small displacement, according to the principle of distorted model, the gravity similarity criterion followed by the abnormal model is,

$$
\lambda_{u}^{2} /\left(\lambda_{g} \lambda_{h}\right)=1
$$

While $\lambda_{g}=1$

We can get the speed of the vertical direction,

$$
\lambda_{u}=\lambda_{h}^{1 / 2}
$$

At the same time, we can get,

$$
\lambda_{t}=\lambda_{l} / \lambda_{h}{ }^{1 / 2}
$$


Because $\mu=p$

Simultaneous:

According to $\operatorname{Re}=\frac{u l}{v}$

$$
\frac{\lambda_{h} \lambda_{u} \lambda_{l}^{1 / 2}}{\lambda_{v}}=1
$$

We can get,

$$
\lambda_{\mathrm{R}}=\frac{\lambda_{l}^{1 / 2}}{\lambda_{h}}
$$

According to the resistance similarity criterion of distorted model,

$$
\lambda_{u}=\frac{1}{\lambda_{n}} \lambda_{R}^{2 / 3} \lambda_{J}^{1 / 2}
$$

Because it is flat panel hypothesis, wetted perimeter scale of ship model is equal to horizontal ratio rule, model roughness ratio can be obtained,

$$
\lambda_{n}=\frac{\lambda_{h}^{2 / 3}}{\lambda_{l}^{1 / 2}}
$$

\section{CORRELATION PARAMETERS OF ABNORMAL SHIP MODEL}

According to the velocity ratio rule, we can get correlation ratio rules of abnormal ship model:

Horizontal ratio rule $\lambda_{l}$

Vertical ratio rule $\lambda_{h}$

Speed ratio rule $\lambda_{l}^{1 / 2}$

Time ratio rule $\lambda_{t}=\lambda_{l} / \lambda_{u}=\lambda_{l} / \lambda_{h}{ }^{1 / 2}$

Horizontal acceleration ratio rule,

$$
\lambda_{a}=\lambda_{h}{ }^{1 / 2} / \lambda_{l}{ }^{1 / 2}
$$

Reynolds number ratio rule,

$$
\lambda_{\mathrm{Re}}=\frac{\lambda_{l}^{1 / 2}}{\lambda_{h}}
$$

Roughness ratio rule,

$$
\lambda_{n}=\frac{\lambda_{h}^{2 / 3}}{\lambda_{l}^{1 / 2}}
$$

\section{ROTATING DIAMETER ANALYSIS OF ABNORMAL SHIP MODEL}

We can choose calculation formula for the rotational diameter of a single river boat, the estimation formula can be estimated tactical diameter accurately in the initial stage of the ship design, and so it can be used to analyze the influence factors of the rotating diameter of the abnormal ship model in the flow model. Formula is as follows [3],

Aspect ratio is greater than 1 ,

$$
D=2 C \frac{k_{1}}{k_{2}} \frac{\nabla}{A_{R}}
$$

Aspect ratio is less than 1 ,

$$
D=2 C \frac{k}{k} \frac{\nabla}{S}\left(\frac{1}{n h_{R}{ }^{2}}+\frac{1}{A_{R}}\right)
$$

C-CCoefficient $(1.0 \sim 1.4)$, When the rudder is located in the wake, the smaller value is taken;

$\nabla$ - D Drainage volume;

$s$ - - Ship longitudinal section below the waterline;

\begin{tabular}{|c|c|c|c|c|c|c|c|c|c|}
\hline 焉 & 总 & 吾国 & 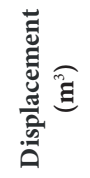 & 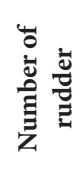 & 宫 & 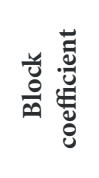 & $\sum_{\Sigma}^{\infty} \Xi$ & 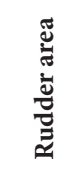 & 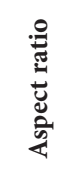 \\
\hline Symbol & $\mathbf{L}$ & $\mathbf{H}$ & $\nabla$ & $\mathbf{n}$ & d & $\mathrm{Cb}$ & $\mathbf{m}$ & AR & $\lambda$ \\
\hline Parameter & 43.6 & 10 & 750 & 1 & 2.100 & 0.819 & 750 & 3.40 & 1.3 \\
\hline
\end{tabular}

$n$ - - Number of rudder;

$h_{R}$ - - Height of rudder;

$A_{R}$ - - Area of rudder;

$k_{1}, k_{2}$ Can get by checking the table of the formula.

Using the formula to analyze different abnormal rate conditions of abnormal model rotation, the list is as follows (tab. 1).

Tab. 1 Related data of a river boat 
According to the above data, we can get the geometry ratio $\lambda$, and obtain $e=1,1.25,1.5,1.75$ four variable rate of the rudder angle $\left(20^{\circ}\right)$, the ship model rotary diameter data is as follows,

Tab. 2 Ship mode turning diameter with four different variable rate

\begin{tabular}{|c|c|c|c|c|}
\hline Abnormal rate e & 1 & 1.25 & 1.5 & 1.75 \\
\hline Rotary diameter $(\mathbf{m})$ & 3.78 & 4.72 & 5.63 & 6.61 \\
\hline
\end{tabular}

When $\mathrm{e}=1$, the ship model and actual ship are normal similarity, rotary diameter is normal similarity. With the increase of the abnormal rate, the rotary diameter of the ship model can't correctly reflect rotation, and the rotation is smaller than horizontal ratio rule.

The calculation of the ship's rudder area is $\lambda_{A R}=\lambda_{l}^{2}$. It is not realistic to determine the area of rudder in accordance with the abnormal ratio of abnormal ship model, it leads to rate change of abnormal ship model is higher, and rotary ratio is smaller than horizontal ratio rule. We can consider that the ratio of rudder is the square of the middle value between the horizontal ratio and the vertical ratio,

$$
\begin{gathered}
\lambda_{A R}=\lambda_{1}^{2}\left(\lambda_{1} \in\left(\lambda_{h}, \lambda_{l}\right)\right) \\
\lambda_{1}=\left(\lambda_{h}+\lambda_{l}\right) / 2
\end{gathered}
$$

Calculation results are as follows,

Tab.3 Ship mode turning diameter with four different variable rate after modified rudder area

\begin{tabular}{|c|c|c|c|c|}
\hline Distortion Ratio e & 1 & 1.25 & 1.5 & 1.75 \\
\hline Turning Diameter $(\mathbf{m})$ & 3.78 & 3.77 & 3.24 & 2.88 \\
\hline
\end{tabular}

After using new abnormal ratio of rudder, results were significantly better than be obtained in Table 2, but the higher the abnormal rate, the more deviation from the ideal data. Therefore, in the case of large abnormal rate, Rudder area ratio $\lambda_{1}=\left(\lambda_{h}+\lambda_{l}\right) / 2$, as close as possible to the horizontal ratio rule of abnormal ship model.

The above calculation analysis is based on the conclusions drawn from the empirical formula, but it can reflect some factors that affect the rotating diameter of the abnormal ship model.

\section{MANEUVERABILITY ANALYSIS OF ABNORMAL SHIP MODEL}

\section{MANEUVERABILITY INDEX OF ABNORMAL SHIP MODEL}

Basic solutions for the equation $K-T$,

$$
r=K \delta\left(1-e^{t / T}\right)
$$

$r$ - Ship angular velocity;

$K-$ Rotational index of ship;

$\delta$ __ Ship rudder angle;

$T$ _Ludder index;

Integral to the formula:

$$
\Psi=T K \delta \int\left(1-e^{1 / T}\right) d \frac{1}{T}+C
$$

Because $r=0$, head angle of ship model $\Psi=0$, we can obtain,

$$
C=-T K \delta
$$

And then get,

$$
\Psi=K \delta\left(1-T+T e^{-t / T}\right)
$$

We can get the curve of the rotation angle and the angle of rotation by using the above two formulas, as shown in Fig. 1 and Fig.2,

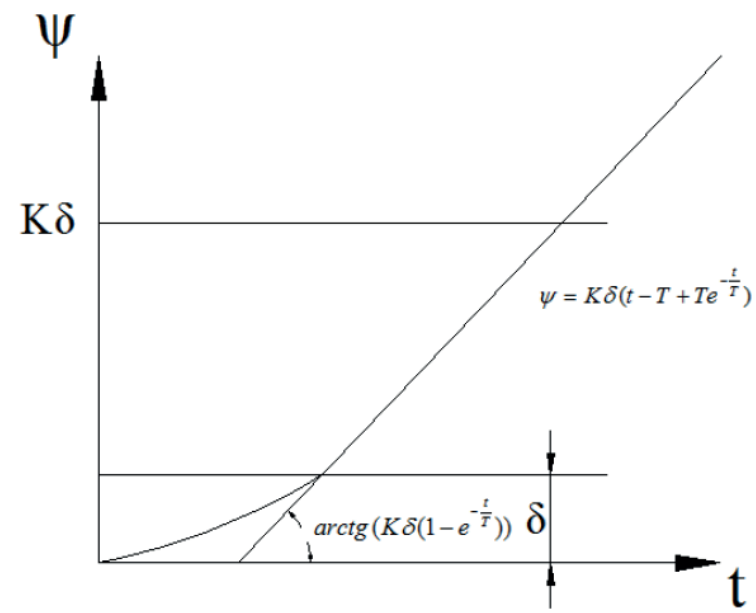

Fig. 1 The curve of the head angle with time change in step steering case

If maneuverability ratio of ship model and actual ship is $\lambda_{K}=\lambda_{T}=1$, it shows that ship model and the real ship are normal similarity. Curves from Fig.1 can be analyzed, when $T>0$ and $T \rightarrow \infty$, turn head angular velocity $r$ infinitely close to a straight line $r=K \delta$; when $T=3 t$ and $r=0.05 K \delta$ it has become almost stable. 


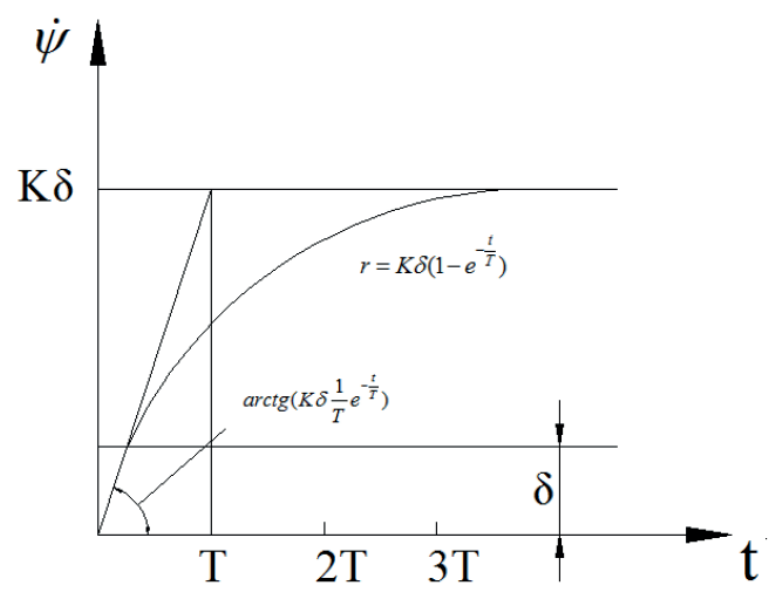

Fig. 2 The curve of the angular velocity with time change in step steering case

From the curve of Fig. 2, the curve of the rotation angle is close to the line.

The speed of the ship entering stable cyclotron is determined by the ship's maneuverability index $\mathrm{T}$, the change of angular velocity of varying rate in different time, analytical data are shown in Tab.4,

We can see from Tab.4, when $\lambda_{T}=0.5, t=4.5 T$, entering constant rotation. But when $\lambda_{T}=1.0,1.5,2.0,4.0$, Ship mode enter constant rotation at,

$t=6 T, 13 T, 19 T, 25 T$.

So we can get, when $\lambda_{T}<1.0$, the time of constant rotation is shorter than the time of normal ship model. But when $\lambda_{T}>1.0$, the time of constant rotation is longer than the time of normal ship model, it is showed that the smaller the rudder index is, the more rapidly the abnormal ship model is fixed.

The rotational index $\mathrm{K}$ of ship model can be seen from Fig.2, the angular velocity of the ship tends to be constant with the increase of time. In the case of a certain angle of the rudder, the greater the index $\mathrm{K}$ is, the greater the angular velocity of the ship is when it is in constant rotation. So, for the abnormal ship model, when $\lambda_{K}<1.0$, the angular velocity of the abnormal ship model is smaller than the normal model. But when $\lambda_{K}>1.0$, the angular velocity of the abnormal ship model is bigger than the normal model.
If rotary index and the index of rudder should be considered at the same time, we can analysis and discuss under different conditions [4]。

(1) $\lambda_{T}<1.0, \lambda_{K}<1.0$, according to Figure 5.2, the angular velocity of the abnormal ship model is bigger than the real one, the time to enter constant rotation is smaller than real ship, steering performance of ship model is better than real ship at this time.

(2) $\lambda_{T}>1.0, \lambda_{K}>1.0$, the angular velocity of the abnormal ship model is smaller than the real one, the time to enter constant rotation is longer than real ship, steering performance of ship model is worse than real ship.

(3) $\lambda_{T}<1.0, \quad \lambda_{K}>1.0$, the angular velocity curve of abnormal ship model and real ship have an intersection, angular velocity of abnormal ship model is greater than that of the real ship before the intersection, but it is smaller than real ship after the intersection. In this case, the time to enter constant rotation is less than the real ship. So, the maneuverability of the ship model is better than real ship before the intersection of the curves is generated, after that, it is worse than real ship.

(4) $\lambda_{T}>1.0, \quad \lambda_{K}<1.0$, the time to enter constant rotation of abnormal ship model is longer than the real ship. In this case, the angular velocity curve of abnormal ship model and real ship have an intersection also, angular velocity of abnormal ship model is smaller than that of the real ship before the intersection, the maneuverability of the ship model is worse than real ship. But it is bigger than real ship after the intersection, the maneuverability of the ship model is better than real ship.

\section{SCALE EFFECT CORRECTION OF ABNORMAL SHIP MODEL}

The above demonstration is only in the comparison between abnormal ship model and normal ship model without considering scale effect which exists between real ship and ship model. Therefore, it is necessary to consider scale effect in the study on the problem of abnormal ship model control similarity.

According to prior information of normal ship model, rotational index $\mathrm{K}^{\prime}$ and rudder index T' of the normal ship model are smaller than the real ship, it shows that the rotation of the normal ship model is better than that of the real ship,

Tab.4 The time entering constant rotation at different $\lambda_{T}$

\begin{tabular}{|c|c|c|c|c|c|c|c|c|c|c|c|}
\hline \multirow{2}{*}{$\begin{array}{l}\text { Angular } \\
\text { velocity }\end{array}$} & \multirow{2}{*}{ Variability } & \multicolumn{10}{|c|}{ Time $t$} \\
\hline & & 0.250 & 0.500 & 1.000 & 2.500 & 4.500 & 6.000 & 9.000 & 13.00 & 19.000 & 25.00 \\
\hline r1 & 1 & 0.221 & 0.393 & 0.632 & 0.917 & 0.988 & 1.000 & 1.000 & 1.000 & 1.000 & 1.000 \\
\hline r2 & 0.5 & 0.393 & 0.632 & 0.865 & 0.993 & 1.000 & 1.000 & 1.000 & 1.000 & 1.000 & 1.000 \\
\hline r3 & 1.5 & 0.154 & 0.283 & 0.487 & 0.811 & 0.950 & 0.981 & 0.998 & 1.000 & 1.000 & 1.000 \\
\hline r4 & 2.0 & 0.117 & 0.221 & 0.393 & 0.713 & 0.894 & 0.950 & 0.988 & 0.999 & 1.000 & 1.000 \\
\hline r5 & 4.0 & 0.060 & 0.117 & 0.199 & 0.465 & 0.675 & 0.777 & 0.895 & 0.961 & 0.991 & 1.000 \\
\hline
\end{tabular}


and the rudder performance is better than the real ship. The scale effect modification is usually used to solve these problems in the ship model test $[5,6,7,8]$. In order to ensure that the ship model can simulate the real ship maneuverability correctly, we can ensure that the rudder index T' of ship model should be consistent with the real ship by considering the rotation index Kand course change index $P$ of the ship model, make it to meet the requirements of the ship model test. The calculation formula of course change index is as follows,

$$
P=K\left(1-T+T e^{-1 / T}\right)
$$

According to figure 2, try to ensure that the steering of ship model is consistent with the real ship, that is,

$$
\lambda_{T}=1
$$

At this point, we can see from the chart that the time entering constant rotation of the ship mode is guaranteed. Under the same rudder angle, the angular velocity of the ship model increases with the increase of the rotation index $K$, angular velocity $r$ is proportional to $K$, leads to the course change index of ship model is also increasing.

In order to realize the consistency of the rotation index of abnormal ship model and the real ship, we can properly reduce the rudder area, reduction should be based on the results of the fixed rate test.

\section{PROPELLER SIMILAR ANALYSIS OF ABNORMAL SHIP MODEL}

For abnormal ship model, horizontal ratio is different from vertical ratio, In the design of the ship model propeller, the propeller should be special-shaped, that is oval. As everyone knows, propeller pushes ship forward by rolling, so the propeller of the ship should be circular.

The resistance of abnormal ship model has the following rules [9]:

(1) When the speed of ship is low, the resistance of the abnormal ship model is close to the normal model; While at high speed, large variation rate of ship model is subject to great resistance.

(2)When in the same speed, the ship model resistance increases with the increase of the variation rate.

(3) With the increase of speed, resistance increase. When the speed is low, increasing speed is slow, speed is high, increasing speed is fast.

(4)When speed is low, friction resistance accounts for most of the total resistance. With the speed increase, the proportion of residual resistance is growing.

In order to ensure the speed of the ship and the ship is similar, we can improve the driving force of the propeller in the ship model test. There are two choices: improving the speed of propeller or increasing propeller area. To increase the speed of propeller, propeller can't meet the motion similarity, we can consider second ways. In the design of the abnormal ship model, propeller is designed according to the vertical ratio to meet motion similarity, to get more ideal test data.

\section{CONCLUSIONS}

Through the derivation of similarity of abnormal ship model, the similarity relationship between abnormal ship model and real ship is obtained. The maneuvering problems of the ship model and real ship are analyzed by using the empirical formula. Although calculated data may not be entirely consistent with data obtained from the test, it also contains some of the necessary factors that affect the maneuverability of the ship. So the data obtained can be used to analyze the influence of abnormal ship model variable rate on rotary ratio. With the increase of the variable rate, the turning quality of ship model becomes worse.

Due to the lack of abnormal ship model test data, there are many problems in the theoretical research. But with the increase of test data, the existing problems of the abnormal ship model will be solved and widely used.

\section{BIBLIOGRAPHY}

1. Cai, R-Z, Cai, C. Similarity problem of small scale ship model. China Harbor Construction, 2005.(4):26 28.

2. Gong, Y-Q, Zhou, H-X, Zheng, B-Y. Related problems in the test of the abnormal ship model. Northeast water conservancy and hydropower,2004(8): 37 39 .

3. Katsuro K. On the Maneuvering Performance of a Ship with the Parameter of Loading Condition. SNAJ, Vol 12, No 168, pp 112-130,1990

4. Li, W-S. Preliminary Study on Vertical Velocity Distribution of Distorted River Model. Journal of Waterway and Harbor, 2004.

5. Liu, M-J, Guo, Z. Study on calculation method of ship maneuverability index. Journal of Wuhan University of Technology, 2003(4):226 228.

6. Muk, CO, Salina, CC, Arthur, TB, Edmond, YM, and Soon KT. Simulating ship maneuvers in deep and coastal waters. Journal of ship research, Vol 51, No 3, pp 204-216,2007.

7. Wu, X-H, Liu, Z-Y. Ship maneuverability. Beijing: National Defense Industry Press, 2005.

8. Wang, DJ, Bakountouzis, L, and Katory, M. Prediction of Ship Hydrodynamic Derivatives in Shallow and Restricted Waters. International Shipbuilding Progress, Vol 47, No 5, pp 56-62,2000. 
9. Yuan, Z-X. Study on the similarity of the performance of the abnormal ship model and real ship. Journal of Shanghai Institute of Marine Transportation Science, 1999.

10. Zhu, D-X, Shen, H-C, and Hong, F-W. The framework of ship model numerical towing tank and research fundament in China. Journal of Hydrodynamics. Vol 2, No 5, pp 109-110,2008.

\section{CONTACT WITH THE AUTHOR}

Chuang Cai, A.P.

School of River and Ocean Engineering Chongqing Jiaotong University 40074 Chongqing, China

e-mail:Caichuang@sina.com

CHINA 